\title{
Does education offset the effect of maternal disadvantage on childhood anaemia in Tanzania? Evidence from a nationally representative cross-sectional study
}

\author{
Olaide O. Ojoniyi ${ }^{1,2^{*}}$ (D), Clifford O. Odimegwu ${ }^{2}$, Emmanuel O. Olamijuwon ${ }^{2,3}$ and Joshua O. Akinyemi $i^{2,4}$
}

\begin{abstract}
Background: Despite being preventable, anaemia is a major public health problem that affects a sizable number of children under-five years globally and in Tanzania. This study examined the maternal factors associated with the risk of anaemia among under-five children in Tanzania. We also assessed whether higher maternal education could reduce the risks of anaemia among children of women with poor socio-economic status.

Methods: Data was drawn from the 2015-16 Tanzania demographic and health survey and malaria indicator survey for 7916 children under five years. Adjusted odds ratios were estimated by fitting a proportional odds model to examine the maternal risk factors of anaemia. Stratified analysis was done to examine how the relationship differed across maternal educational levels.

Results: The findings revealed that maternal disadvantage evident in young motherhood [AOR:1.43, 95\%Cl:1.16-1.75], no formal education [AOR:1.53, 95\%Cl:1.25-1.89], unemployment [AOR:1.31, 95\%Cl:1.15-1.49], poorest household wealth [AOR:1.50, 95\%Cl:1.17-1.91], and non-access to health insurance [AOR:1.26, 95\%Cl: 1.03-1.53] were risk factors of anaemia among children in the sample. Sub-group analysis by maternal education showed that the risks were not evident when the mother has secondary or higher education. However, having an unmarried mother was associated with about four-times higher risk of anaemia if the mother is uneducated [AOR:4.04, 95\%Cl:1.98-8.24] compared with if the mother is currently in union.

Conclusion: Findings from this study show that a secondary or higher maternal education may help reduce the socioeconomic risk factors of anaemia among children under-5 years in Tanzania.
\end{abstract}

Keywords: Anaemia, Under-five children, Maternal characteristics, TDHS-MIS, Tanzania

\section{Background}

Anaemia, particularly among children under 5 years, is a public health problem of serious concern. In East Africa, approximately $75 \%$ of under-five children suffer from anaemia [1]. In regions within Tanzania, the prevalence of anaemia among under-five children ranges between 44 and $76 \%$ [2]. In 2010, the Tanzania demographic and

\footnotetext{
* Correspondence: olaideojoniyi@gmail.com

${ }^{1}$ Implementation Science Department, The Wits Reproductive Health \& HIV Institute, P.O Box 2193, Johannesburg, South Africa

${ }^{2}$ Demography and Population Studies Programme, Schools of Social Sciences and Public Health, University of the Witwatersrand, Johannesburg, South Africa

Full list of author information is available at the end of the article
}

health survey reported the prevalence of anaemia in the Lake Zone to be $55 \%$. In most health facilities in Tanzania, severe anaemia is among the causes of admission and mortality in the paediatrics' ward [3].

Poor nutritional status, micro-nutrient deficiencies, intestinal worms, HIV infection, haematological malignancies and chronic diseases such as sickle cell disease are known to be contributing factors of the high prevalence of anaemia [1]. Its implications for health, as well as social and economic development, are diverse. Among children, it weakens their mental and physical development resulting in poor academic performance and employability in later years [3].

(C) The Author(s). 2019 Open Access This article is distributed under the terms of the Creative Commons Attribution 4.0 International License (http://creativecommons.org/licenses/by/4.0/), which permits unrestricted use, distribution, and 
Over the years, diverse intervention programs such as food fortification, vitamin A for under-five children and iron folate supplement for pregnant women have been implemented with the aim of reducing childhood anaemia in Tanzania [3]. Despite these interventions, the prevalence of anaemia remains high. Given its prevalence and the developmental challenges that it poses for children, understanding the risk factors of anaemia is expected to drive interventions and inform existing prevention measures towards achieving the Post 2015 Sustainable development goal 3 for improvement in health and well-being.

Several studies have examined the socio-demographic factors associated with child health and survival using malnutrition and mortality as key proxies for child health. In the absence of urgent treatment, anaemic children also suffer severe complications [4]. Although some factors such as malaria, HIV infections and malnutrition are known to increase anaemia risk among children, other potential risk factors such as maternal education and other socio-economic characteristics of the mother may increase the risk of anaemia among children [5-7].

Evidence of the importance of maternal education continues to emerge $[6,8-10]$. Studies have shown that maternal education can reduce risks of poor child health through higher health knowledge, adherence to recommended feeding practices for children, and increased command over resources $[10,11]$. Highly educated mothers can better understand printed and audio health information, convey their children's health needs at health facilities and better understand complex treatment regimens [11]. Given these benefits, it is likely that disadvantages in other socio-economic characteristics may have little effects on the children of better-educated mothers.

Yet, in Tanzania and in part of sub-Saharan Africa where anaemia is prevalent, evidence of the benefit of maternal education in reducing the risks associated with maternal disadvantage are scarce. As a result, we examined if maternal education might reduce the risk of anaemia in under-five children whose mothers are disadvantaged in other socio-economic indices. To clearly understand this relationship, we analyzed the recent dataset from the Tanzania demographic and health survey and malaria indicator survey to illuminate the prevalence and associated factors of anaemia across selected socio-demographics. Our study builds upon Mosley and Chen's 1984 analytical framework for the study of maternal and child survival in developing countries [6]. We argue that the risk of anaemia in children may be reduced if the socio-demographic and economic characteristics relating to the mothers are improved. An awareness of this relationship is expected to facilitate improved targeted interventions for reducing the risks of anaemia among under-five children in Tanzania.

\section{Data and methods}

Data for this study was drawn from the children recode dataset of the 2015-16 Tanzania demographic, health and malaria indicator survey. The dataset contains information that may be used to monitor and evaluate the demographic and health indicators of children under 5 years.

In order to provide estimates intended to be representative of the entire country, a two-stage sample design was used. This sampling design allowed the estimation of indicators for each of the 30 regions of the country. The first stage of the sampling design, involved the selection of 608 clusters, consisting of enumeration areas delineated for the 2012 Tanzania Population and Housing Census [12]. In the second stage, 22 households from each of the clusters was systematic selected. This was done after a complete households listing was carried out for all 608 selected clusters in the country [12]. This yielded a total representative probability sample of 10,233 children under 5 years born to 13,266 women who completed the interviews and reside in any of the 13,376 households selected for participation in the survey. In all the households, with the parent's or guardian's consent, children age 6-59 months were tested for anaemia and malaria.

A sub-sample of 2219 children who did not participate in the anemia module were further excluded from analysis. This comprised of children who were not alive or physically present at the time of data collection, children whose parents or guardian refused, and those who were less than 6 months of age at the time of data collection. We also excluded 98 children with missing information on key demographic, maternal, and household characteristics. This led to a final analytic sample of 7916 children under five (6-59 months) years in Tanzania who had complete information on all socio-demographic variables and whose anthropometric data and anaemia data were collected.

\section{Variable description \\ The outcome variable}

The main outcome variable for this study was anaemia status, adjusted for altitude measured in grams per deciliter $(\mathrm{g} / \mathrm{dl})$. The variable was categorized by haemoglobin levels ranging from no anaemia (0), mild (1) moderate (2), and severe anaemia (3). During the survey, all children age 6-59 months living in the selected households were assessed for anaemia through finger prick or, in the case of young children, heel prick blood testing using the HemoCue blood haemoglobin testing system which measures the concentration of haemoglobin in the blood. The anaemia cutoff points used in this study were those recommended by the World Health Organization (WHO) for children [13]. Haemoglobin levels below $7.0 \mathrm{~g} / \mathrm{dl}$ were considered as severe anaemia, levels between $7.1 \mathrm{~g} / \mathrm{dl}$ and $9.9 \mathrm{~g} / \mathrm{dl}$ were considered as moderate anaemia and levels 
between $10.0 \mathrm{~g} / \mathrm{dl}$ and $10.9 \mathrm{~g} / \mathrm{dl}$ are considered as mild anaemia for all children in the sample $[14,15]$. The mothers of children whose anaemia level was severe were asked whether information on their child's health can be given to a doctor at a specified health facility for follow up.

\section{Predictor variables}

The predictor variables included in the study are socio-economic and demographic variables namely: mother's educational attainment (no education, primary, secondary +); age group in years (15-24, 25-34, 35-49); marital status (not married, currently married and formerly married); employment status (not working and currently working); place of residence (mainland-urban, mainland-rural, Zanzibar-urban, and Zanzibar-rural); mother's body mass index (underweight, normal, overweight, and severe obesity). Household wealth status was assessed using a principal component analysis that combined scores for each household based on the number and kinds of consumer goods they own, ranging from a television to a bicycle or car, plus housing characteristics, such as source of drinking water, toilet facilities, and flooring materials. Households were subsequently ranked and divided into quintiles of five equal categories (poorest, poorer, middle, richer and richest) with each accounting for $20 \%$ of the population [12]. Health insurance (no health insurance and has health insurance). Child's characteristics included child sex (male and female); child age in months (6-23, 24-47, and 48-59 months), birth type (single and multiple), number of siblings and Child's BMI (low, normal, overweight, obese).

\section{Statistical analysis}

Frequency distributions were used to describe the profile of children in the sample. The outcome variable was also tabulated against the predictor variables and covariates to assess the prevalence of anaemia in the sample. Chi-square $\left(x^{2}\right)$ tests were used to determine statistically significant differences in the prevalence of anaemia across the predictor variables. We estimated adjusted odds ratios (AORs) and 95\% confidence intervals (CIs) for the association between the predictors and the outcome using a proportional odds model, a regression model for an ordinal outcome variable [16]. This model uses cumulative probabilities to a threshold, thereby making the whole range of ordinal categories binary at that threshold. All model diagnostics inclusive of Wald, Brant, and Score test provided evidence that the model fits reasonably for our data. Robust standard errors were estimated to account for sampling errors.

Furthermore, we considered how the relationship between the predictors and the risk of anaemia among children may differ by maternal educational attainment by fitting a proportional odds regression model stratified by maternal level of education. G-Power version 3.1.9.2 was used for Post-hoc power estimation to ascertain that there is sufficient sample size for stratified analysis and the result showed that the statistical power was greater than $80 \%$ [17]. Interpretation of the results was done using odds ratios (OR) with a confidence interval of 95\%. Results for analysis were weighted to adjust for sampling error and the clustering of the sample. Data management and analyses were performed in Stata/MP version 15.1 (StataCorp, College Station, USA).

\section{Results}

\section{Descriptive profile of study sample}

The total sample for this study comprised of 7916 children under 5 years in Tanzania. As presented in Table 1, slightly above one-quarter (28\%) of the children were born to adolescent and young women between 15 and 24 years of age. Only about $5 \%$ of the children were born to unmarried women while the majority $(85 \%)$ were born to women who are currently married. More than half of the children have a mother with primary education while almost one-quarter have a mother with no formal education. Most $(80 \%)$ of the children have a mother who is currently working. About $25 \%$ of the children reside in the urban area while the rest reside in the rural areas of the Mainland (73\%) and the Zanzibar (2.0\%). Less than one-tenth of the children had medical insurance. About $68 \%$ of the children had a mother with a normal BMI between (18.5-24.9) while about $25 \%$ had a mother who is either overweight or obese. Overall, $46 \%$ of the children reside in the poorest or poorer household and about $34 \%$ reside in the richer or richest household. The majority of the children (97\%) were single births and about $61 \%$ of the children were 2 years or older. Only about three-quarter of the children have a normal BMI according to the WHO growth standard.

\section{Prevalence of Anaemia across maternal socio- demographic characteristics}

In Table 2, we examined the prevalence of anaemia across selected characteristics. More than half of the children aged 6-59 months in the sample were anaemic with about $2 \%$ manifesting severe anaemia. The prevalence of anaemia is significantly different $(p<0.05)$ across maternal characteristics, excluding maternal marital status. We found that anaemia was more common among children of adolescent and young women $(64 \%)$ and lowest among children of middle-aged (35-44 years) women (54\%). Both severe (3\%) and mild/moderate (64\%) anaemia are more common among children of women with no formal education although more than half (55\%) of the children of women with secondary or higher education are anaemic. Severe anaemia is more common among children whose mothers resides in the mainland while mild/moderate anaemia is more 
Table 1 Descriptive Characteristics of the Study Population (Source: TDHS, 2015-16)

\begin{tabular}{|c|c|c|}
\hline Characteristics & $\begin{array}{l}\text { Sample } \\
n=7916\end{array}$ & $\begin{array}{l}\text { Percentage } \\
\%\end{array}$ \\
\hline \multicolumn{3}{|l|}{ Mother's Age Group } \\
\hline $15-24$ & 2153 & 28.2 \\
\hline $25-34$ & 3567 & 45.2 \\
\hline $35-49$ & 2196 & 26.6 \\
\hline \multicolumn{3}{|l|}{ Marital Status } \\
\hline Not Married & 346 & 4.9 \\
\hline Currently Married & 6768 & 84.5 \\
\hline Formerly Married & 802 & 10.6 \\
\hline \multicolumn{3}{|l|}{ Educational Attainment } \\
\hline No Education & 1742 & 21.7 \\
\hline Primary & 4758 & 64.5 \\
\hline Secondary+ & 1416 & 13.8 \\
\hline \multicolumn{3}{|l|}{ Employment Status } \\
\hline Not Working & 1655 & 20.0 \\
\hline Currently Working & 6261 & 80.0 \\
\hline Number of Siblings & $\begin{array}{l}\text { median } \\
3\end{array}$ & $\begin{array}{l}\text { S.Dev } \\
2.54\end{array}$ \\
\hline \multicolumn{3}{|l|}{ Place of Residence } \\
\hline Mainland - Urban & 1550 & 24.8 \\
\hline Mainland - Rural & 5193 & 72.6 \\
\hline Zanzibar - Urban & 219 & 0.7 \\
\hline Zanzibar - Rural & 954 & 1.9 \\
\hline \multicolumn{3}{|l|}{ Health Insurance } \\
\hline No Health Insurance & 7358 & 92.4 \\
\hline Health Insurance & 558 & 7.6 \\
\hline \multicolumn{3}{|l|}{ Mother's BMI } \\
\hline Under Weight & 560 & 6.8 \\
\hline Normal & 5300 & 68.1 \\
\hline Overweight & 1864 & 22.6 \\
\hline Severe Obesity & 192 & 2.4 \\
\hline \multicolumn{3}{|l|}{ Wealth Status } \\
\hline Poorest & 1810 & 24.4 \\
\hline Poorer & 1658 & 22.0 \\
\hline Middle & 1565 & 19.6 \\
\hline Richer & 1628 & 18.2 \\
\hline Richest & 1255 & 15.8 \\
\hline \multicolumn{3}{|l|}{ Birth Type } \\
\hline Single & 7673 & 96.9 \\
\hline Multiple & 243 & 3.1 \\
\hline \multicolumn{3}{|l|}{ Child's Sex } \\
\hline Male & 3971 & 50.6 \\
\hline Female & 3945 & 49.4 \\
\hline Child's Age & & \\
\hline
\end{tabular}

Table 1 Descriptive Characteristics of the Study Population (Source: TDHS, 2015-16) (Continued)

\begin{tabular}{lll}
\hline Characteristics & $\begin{array}{l}\text { Sample } \\
n=7916\end{array}$ & $\begin{array}{l}\text { Percentage } \\
\%\end{array}$ \\
\hline 6-23 months & 3052 & 38.8 \\
24-47 months & 3297 & 41.8 \\
48-59 months & 1567 & 19.4 \\
Child's BMl & & \\
Low & 989 & 3.7 \\
Normal & 6092 & 76.0 \\
Overweight & 1185 & 15.7 \\
Obese & 339 & 4.6 \\
\hline Frequency distributions are unweighted while percentages are weighted
\end{tabular}

Frequency distributions are unweighted while percentages are weighted

common among children whose mothers reside in the Zanzibar. More than half $(60 \%)$ of the children whose mothers do not have a health insurance are anaemic.

The prevalence of anaemia is also higher among children of underweight mothers (61\%) and lowest among children whose mothers are obese (43\%). Across wealth status, almost two-thirds of the children whose mother reside in the poorest households are anaemic with almost $2 \%$ manifesting severe anaemia. Slightly more than half of those whose mothers resides in the richest households are also anaemic.

Examining the prevalence of anaemia across selected child characteristics, we found a statistically significant difference in the prevalence of anaemia by child's sex $(p<0.05)$, child's age $(p<0.05)$, and child's body mass index $(p<0.05)$. Anaemia was more prevalent among children with multiple births (61\%), boys $(60 \%)$, children under 2 years (75\%) and children with a low body mass index (68\%).

\section{Maternal socio-demographic factors associated with the risk of Anaemia}

Results from Table 3 show the socio-demographic characteristics associated with the risk of anaemia among children under 5 years while adjusting for covariates. The combined risk of severe, mild or moderate anaemia is higher among children of adolescent and young women [AOR: $1.43,95 \% \mathrm{CI}$ : $1.16-1.75$ ] as well as those of women aged 25-34 years [AOR: 1.22, 95\%CI: $1.05-$ 1.42] compared to children of women who are 35 years or older. Maternal educational attainment is also significantly associated with the risk of anaemia. Children of women with no formal education [AOR: 1.53, 95\%CI: $1.25-1.89$ ] are significantly more likely to be anaemic compared to the children of women with secondary or higher education. Children whose mothers are not working [AOR: 1.31, 95\%CI: 1.15-1.49] are also at a higher risk of anaemia compared to children whose mother are currently working. A higher number of 
Table 2 Prevalence of Anaemia and Associated Factors among Children Under-Five Years (TDHS-MIS, 2015-16)

\begin{tabular}{|c|c|c|c|c|}
\hline \multirow{2}{*}{$\begin{array}{l}\text { Socio-Demographic } \\
\text { Characteristics }\end{array}$} & \multirow{2}{*}{$\begin{array}{l}\% \text { with any } \\
\text { Anaemia }\end{array}$} & \multicolumn{2}{|l|}{ Anaemia severity } & \multirow[b]{2}{*}{$p$-value } \\
\hline & & $\%$ with mild /moderate Anaemia & $\%$ with Severe Anaemia & \\
\hline \multicolumn{5}{|l|}{ Mother's Age Group } \\
\hline $15-24$ & 64.0 & 61.9 & 2.2 & \multirow[t]{3}{*}{0.000} \\
\hline $25-34$ & 57.7 & 56.1 & 1.7 & \\
\hline $35-49$ & 54.4 & 53.1 & 1.3 & \\
\hline \multicolumn{5}{|l|}{ Marital Status } \\
\hline Not Married & 64.7 & 63.7 & 1.0 & \multirow[t]{3}{*}{0.182} \\
\hline Currently Married & 58.2 & 56.4 & 1.8 & \\
\hline Formerly Married & 59.5 & 57.7 & 1.7 & \\
\hline \multicolumn{5}{|l|}{ Educational Attainment } \\
\hline No Education & 66.4 & 63.8 & 2.7 & \multirow[t]{3}{*}{0.000} \\
\hline Primary & 56.7 & 55.2 & 1.5 & \\
\hline Secondary+ & 55.2 & 54.1 & 1.1 & \\
\hline \multicolumn{5}{|l|}{ Employment Status } \\
\hline Not Working & 63.5 & 61.1 & 2.4 & \multirow[t]{2}{*}{0.001} \\
\hline Currently Working & 57.4 & 55.9 & 1.6 & \\
\hline Number of Siblings & 3 & 3 & 3 & 0.581 \\
\hline Place of Residence & & & & 0.000 \\
\hline Mainland - Urban & 54.4 & 53.4 & 1.1 & 0.000 \\
\hline Mainland - Rural & 59.8 & 57.8 & 2.0 & \\
\hline Zanzibar - Urban & 63.9 & 63.6 & 0.3 & \\
\hline Zanzibar - Rural & 67.0 & 66.1 & 0.9 & \\
\hline \multicolumn{5}{|l|}{ Wealth Status } \\
\hline Poorest & 63.8 & 61.4 & 2.3 & \multirow[t]{5}{*}{0.000} \\
\hline Poorer & 61.2 & 58.5 & 2.7 & \\
\hline Middle & 59.8 & 59.0 & 0.8 & \\
\hline Richer & 53.4 & 52.1 & 1.3 & \\
\hline Richest & 51.6 & 50.6 & 1.0 & \\
\hline \multicolumn{5}{|l|}{ Health Insurance } \\
\hline No Health Insurance & 59.5 & 57.7 & 1.8 & \multirow[t]{2}{*}{0.000} \\
\hline Health Insurance & 48.0 & 47.4 & 0.6 & \\
\hline \multicolumn{5}{|l|}{ Mother's BMI } \\
\hline Under Weight & 61.2 & 58.1 & 3.1 & \multirow[t]{4}{*}{0.000} \\
\hline Normal & 61.4 & 59.5 & 1.9 & \\
\hline Overweight & 51.2 & 50.2 & 0.9 & \\
\hline Severe Obesity & 43.2 & 42.2 & 0.9 & \\
\hline \multicolumn{5}{|l|}{ Birth Type } \\
\hline Single & 58.6 & 56.9 & 1.7 & \multirow[t]{2}{*}{0.181} \\
\hline Multiple & 60.8 & 57.2 & 3.6 & \\
\hline \multicolumn{5}{|l|}{ Child's Sex } \\
\hline Male & 60.2 & 58.4 & 1.9 & \multirow[t]{2}{*}{0.025} \\
\hline Female & 57.0 & 55.4 & 1.5 & \\
\hline \multicolumn{5}{|l|}{ Child's Age } \\
\hline 6-23 months & 75.3 & 72.5 & 2.8 & 0.000 \\
\hline
\end{tabular}


Table 2 Prevalence of Anaemia and Associated Factors among Children Under-Five Years (TDHS-MIS, 2015-16) (Continued)

\begin{tabular}{llll}
\hline $\begin{array}{l}\text { Socio-Demographic } \\
\text { Characteristics }\end{array}$ & $\begin{array}{l}\text { \% with any } \\
\text { Anaemia }\end{array}$ & Anaemia severity & \% with Severe Anaemia \\
\cline { 4 - 4 } $24-47$ months & 50.8 & 49.7 & 1.1 \\
$\begin{array}{l}\text { 48-59 months } \\
\text { Child's BMl }\end{array}$ & 42.3 & 41.5 & 0.8 \\
Low & & & \\
Normal & 68.4 & 64.4 & 4.0 \\
Overweight & 57.2 & 55.5 & 1.7 \\
Obese & 62.1 & 60.7 & 1.5 \\
Sample & 62.4 & 61.0 & 1.3 \\
\hline
\end{tabular}

siblings is associated with a higher risk of anaemia among the children [AOR: 1.05, 95\%CI: 1.01-1.08].

The combined risk of severe, mild or moderate anaemia is significantly higher among children whose mothers reside in the urban [AOR: 1.76, 95\%CI: 1.30 2.38] and rural [AOR: 1.39, 95\%CI: 1.16-1.66] Zanzibar when compared to children whose mothers resides in urban mainland. Non-access to or non-ownership of health insurance [AOR: 1.26, 95\%CI: 1.03-1.53] is associated with a higher risk of anaemia among the children. Maternal overweight [AOR: 0.79, 95\%CI: 0.69-0.89] and obesity [AOR: 0.62, 95\%CI: 0.43-0.89] compared to a moderate/normal body mass index was significantly associated with a reduced risk of anaemia among children under 5 years.

The risk of anaemia is significantly higher among children living in the poorest [AOR: 1.50, 95\%CI: 1.17-1.91], and poorer [AOR: 1.41, 95\%CI: 1.10-1.80] households compared to those living in the richest households. Underweight [AOR:1.39, 95\%CI: 1.051.85] and overweight [AOR:1.21, 95\%CI: 1.05-1.40] children are significantly at risk of anaemia compared to children with a normal body mass. Older children aged 24-47 months [AOR:0.37, 95\%CI: 0.33-0.42] and those between 48 and 59 months old [AOR:0.27, 95\%CI: $0.23-0.31$ ] are significantly less likely to be anaemic compared to children under 24 months old. Female children [AOR:0.84, 95\%CI: 0.76-0.93] had a significantly lower risk of anaemia compared to males.

The role of maternal education in reducing Anaemia risks among children under five years

In order to understand whether having an educated mother can offset the risk of anaemia associated with having a socio-economically disadvantaged mother, we also present in Table 3, the results from our sub-group analysis by level of educational attainment.

We observe no statistically significant difference in the risk of anaemia in almost all the maternal socio-demographic categories including age, employment status, wealth status, health insurance or body mass, particularly among children of women with secondary or higher education. However, maternal residence in urban Zanzibar [AOR:2.28, 95\%CI: 1.48-3.54] or rural Zanzibar [AOR:1.84, 95\%CI: $1.30-2.60]$ remains significantly associated with the risk of anaemia among under-five children even with higher levels of maternal education.

Although we found no statistical evidence that marital status was associated with the risk of anaemia in the main model, results from Table 3 shows that children of unmarried mothers [AOR:4.04, 95\%CI: 1.98-8.24] with no formal education were about four times more likely to be anaemic compared to children of currently married women with similar levels of education. Similarly, the children of uneducated mothers residing in the poorest [AOR:2.68, 95\% CI: 1.28-5.60] or poorer households [AOR: 2.21, 95\%CI: $1.05-$ 4.66] were significantly more likely to be anaemic compared to the children of women with similar levels of education but residing in the richest households. Maternal unemployment [AOR:1.31, 95\%CI: 1.15-1.49] also remained significantly associated with anaemia among children of women with no formal education.

\section{Discussion}

In this study, we attempted to identify the maternal socio-demographic characteristics associated with the risks of anaemia as well as how access to educational opportunities for mothers may reduce the risk for children under-five in Tanzania. We observed a high level of anaemia among children under-5 years in Tanzania. This confirms the severity of anaemia as a public health challenge that needs immediate actions and measures in Tanzania based on the WHO criteria. This finding is similar to another study in Tanzania [18]. Prior studies have noted high malaria infection, nutritional deficiencies and sickle cell disease to be contributing factors to this high prevalence [3]. We also noted variations in the severity of anemia by place and region of residence. Our finding that anaemia is more common in Zanzibar is supported by a recent report of the 2014 Tanzania 
Table 3 Risk Factors of Anaemia Among Children Under-Five Years in Tanzania Stratified by Maternal Educational Attainment (TDHSMIS, 2015-16)

\begin{tabular}{|c|c|c|c|c|}
\hline \multirow[t]{2}{*}{$\begin{array}{l}\text { Socio-Demographic } \\
\text { Characteristics }\end{array}$} & $\begin{array}{l}\text { All Children Sample } \\
(n=7916)\end{array}$ & $\begin{array}{l}\text { No Education } \\
(n=1742)\end{array}$ & $\begin{array}{l}\text { Primary } \\
(n=4758)\end{array}$ & $\begin{array}{l}\text { Secondary+ } \\
(n=1416)\end{array}$ \\
\hline & \multicolumn{4}{|c|}{ Adjusted Odd Ratios [95\% Cl] } \\
\hline \multicolumn{5}{|l|}{ Mother's Age Group } \\
\hline $15-24$ & $1.43^{* * *}[1.16,1.75]$ & $1.15[0.74,1.79]$ & $1.55^{* * *}[1.20,2.00]$ & $1.62[0.90,2.89]$ \\
\hline $25-34$ & $1.22^{*}[1.05,1.42]$ & $1.29[0.95,1.76]$ & $1.21^{*}[1.00,1.46]$ & $1.55[0.97,2.48]$ \\
\hline $35-49$ & Reference & Reference & Reference & Reference \\
\hline \multicolumn{5}{|l|}{ Marital Status } \\
\hline Not Married & $1.09[0.87,1.38]$ & $4.04^{* * *}[1.98,8.24]$ & $1.08[0.80,1.44]$ & $0.86[0.57,1.31]$ \\
\hline Currently Married & Reference & Reference & Reference & Reference \\
\hline Formerly Married & $1.04[0.89,1.22]$ & $0.95[0.68,1.32]$ & $1.07[0.87,1.31]$ & $1.13[0.71,1.81]$ \\
\hline \multicolumn{5}{|l|}{ Educational Attainment } \\
\hline No Education & $1.53^{* * *}[1.25,1.89]$ & & & \\
\hline Primary & $1.06[0.90,1.26]$ & & & \\
\hline Secondary+ & Reference & & & \\
\hline \multicolumn{5}{|l|}{ Employment Status } \\
\hline Not Working & $1.31^{* * *}[1.15,1.49]$ & $1.62^{* *}[1.21,2.16]$ & $1.21^{*}[1.03,1.43]$ & $1.34[0.97,1.85]$ \\
\hline Currently Working & Reference & Reference & Reference & Reference \\
\hline Number of Siblings & $1.05^{* *}[1.01,1.08]$ & $1.05[0.98,1.12]$ & $1.06^{* *}[1.02,1.10]$ & $0.97[0.86,1.10]$ \\
\hline \multicolumn{5}{|l|}{ Place of Residence } \\
\hline Mainland - Urban & Reference & Reference & Reference & Reference \\
\hline Mainland - Rural & $0.89[0.76,1.05]$ & $0.65^{*}[0.44,0.97]$ & $0.95[0.78,1.17]$ & $0.99[0.66,1.50]$ \\
\hline Zanzibar - Urban & $1.76^{* * *}[1.30,2.38]$ & $0.49[0.22,1.08]$ & $1.87[0.98,3.56]$ & $2.28^{* * *}[1.48,3.54]$ \\
\hline Zanzibar - Rural & $1.39^{* * *}[1.16,1.66]$ & $0.9[0.58,1.38]$ & $1.38^{*}[1.05,1.82]$ & $1.84^{* * *}[1.30,2.60]$ \\
\hline \multicolumn{5}{|l|}{ Wealth Status } \\
\hline Poorest & $1.50^{* *}[1.17,1.91]$ & $2.68^{* *}[1.28,5.60]$ & $1.27[0.93,1.74]$ & $2.17[0.87,5.45]$ \\
\hline Poorer & $1.41^{* *}[1.10,1.80]$ & $2.21^{*}[1.05,4.66]$ & $1.34[0.98,1.83]$ & $1.06[0.56,2.01]$ \\
\hline Middle & $1.26[1.00,1.59]$ & $2.06[0.97,4.38]$ & $1.19[0.89,1.60]$ & $0.88[0.50,1.54]$ \\
\hline Richer & $0.96[0.79,1.18]$ & $1.69[0.80,3.56]$ & $0.84[0.64,1.10]$ & $1.12[0.76,1.66]$ \\
\hline Richest & Reference & Reference & Reference & Reference \\
\hline \multicolumn{5}{|l|}{ Health Insurance } \\
\hline No Health Insurance & $1.26^{*}[1.03,1.53]$ & $1.22[0.66,2.25]$ & $1.29[1.00,1.67]$ & $1.34[0.90,2.00]$ \\
\hline Health Insurance & Reference & Reference & Reference & Reference \\
\hline \multicolumn{5}{|l|}{ Mother's BMI } \\
\hline Under Weight & $0.97[0.80,1.18]$ & $1.08[0.69,1.67]$ & $0.9[0.71,1.15]$ & $0.99[0.58,1.69]$ \\
\hline Normal & Reference & Reference & Reference & Reference \\
\hline Overweight & $0.79^{* * *}[0.69,0.89]$ & $0.59^{* * *}[0.44,0.79]$ & $0.86[0.73,1.01]$ & $0.75[0.55,1.03]$ \\
\hline Severe Obesity & $0.62^{*}[0.43,0.89]$ & $0.21^{*}[0.05,0.90]$ & $0.54^{*}[0.33,0.88]$ & $0.89[0.45,1.77]$ \\
\hline \multicolumn{5}{|l|}{ Birth Type } \\
\hline Single & Reference & Reference & Reference & Reference \\
\hline Multiple & $1.38^{*}[1.01,1.87]$ & $1.62[0.92,2.84]$ & $1.09[0.74,1.60]$ & $2.62[0.90,7.57]$ \\
\hline \multicolumn{5}{|l|}{ Child's Sex } \\
\hline Male & Reference & Reference & Reference & Reference \\
\hline Female & $0.84^{* * *}[0.76,0.93]$ & $0.91[0.73,1.13]$ & $0.78^{* * *}[0.69,0.89]$ & $0.97[0.74,1.28]$ \\
\hline
\end{tabular}


Table 3 Risk Factors of Anaemia Among Children Under-Five Years in Tanzania Stratified by Maternal Educational Attainment (TDHSMIS, 2015-16) (Continued)

\begin{tabular}{lllll}
\hline $\begin{array}{l}\text { Socio-Demographic } \\
\text { Characteristics }\end{array}$ & $\begin{array}{l}\text { All Children Sample } \\
(n=7916) \\
\text { Adjusted Odd Ratios [95\% Cl] }\end{array}$ & $\begin{array}{l}\text { No Education } \\
(n=1742)\end{array}$ & $\begin{array}{l}\text { Primary } \\
(n=4758)\end{array}$ & $\begin{array}{l}\text { Secondary+ } \\
(n=1416)\end{array}$ \\
\hline 6-23 months & Reference & Reference & Reference & Reference \\
24-47 months & $0.37^{* * *}[0.33,0.42]$ & $0.52^{* * *}[0.40,0.66]$ & $0.35^{* * *}[0.31,0.41]$ & $0.30^{* * *}[0.22,0.41]$ \\
$48-59$ months & $0.27^{* * *}[0.23,0.31]$ & $0.36^{* * *}[0.27,0.49]$ & $0.25^{* * *}[0.21,0.30]$ & $0.19^{* * *}[0.12,0.29]$ \\
Child's BMl & & & & $1.34[0.95,1.88]$ \\
Low & $1.39^{*}[1.05,1.85]$ & $2.32^{* *}[1.24,4.36]$ & Reference & $0.62[0.30,1.28]$ \\
Normal & Reference & Reference & $1.19[0.99,1.42]$ & Reference \\
Overweight & $1.21^{* *}[1.05,1.40]$ & $0.99[0.74,1.33]$ & $0.85[0.63,1.15]$ & $1.87^{* * *}[1.29,2.71]$ \\
Obese & $1.07[0.84,1.36]$ & $1.52[0.87,2.67]$ & $0.71[0.46,1.1]$ & $1.57[0.81,3.04]$ \\
/Cut1 & $0.79[0.58,1.08]$ & $0.81[0.28,2.31]$ & $2.42[1.56,3.74]$ & $0.86[0.39,1.87]$ \\
/Cut2 & $2.70[1.97,3.7]$ & $2.73[0.96,7.72]$ & $77.3[46.9127 .3]$ & $3.42[1.57,7.44]$ \\
/cut3 & $82.9[57.2120 .2]$ & $75.0[25.0,225.3]$ & $10,794.61$ & $143.0[44.4460 .6]$ \\
AlC & $16,881.3$ & 3859.96 & -5370.3 & 2212.41 \\
Log pseudolikelihood & -8411.65 & -1902.98 & -1079.21 \\
\hline
\end{tabular}

${ }^{*} p<0.05,{ }^{* *} p<0.01,{ }^{* * *} p<0.001$

National Nutrition Survey. Although deworming pills and iron folic acid (IFA) supplements could help prevent the risk of anemia and are critical for the reduction of child morbidity and mortality the report suggests that children in the mainland (71\%) are more likely to be dewormed against Helminthes or intestinal worms compared to Zanzibar resident children (54\%) [19]. About $31 \%$ of women aged $15-49$ years with children under 5 years of age reported not using iron-folic acid supplementation during pregnancy compared to about $37 \%$ of women in the Zanzibar [19].

In this study, maternal education emerges as a significant predictor of anaemia. This finding is consistent with those observed in prior studies in Tanzania [20-24]. Maternal education, particularly at the secondary level, has been linked to improved child health outcomes [13]. This protective benefit of maternal education has been shown to be related to an increased knowledge needed for adequate healthcare and nutrition for children hence its possibility for reducing the risk of anaemia.

Maternal employment status is also associated with anaemia among under-five children in Tanzania, and this may be because working mothers are able to afford quality meal supplements, particularly since one of the major causes of anaemia in developing countries is nutrient deficiency. Unemployment is associated with poor socio-economic status. This is likely to reflect nutritional deficiencies and recurrence of infections which more likely increases the risk of anaemia. This result is similar to a study conducted in Mwanza Tanzania that found that unemployment among caretakers was strongly associated with severe anaemia [3].
We observe that maternal age is negatively associated with anaemia. This result corresponds with results from other studies in Cape Verde and rural Indian communities where children whose mothers were younger were significantly more likely to have anaemia [24-26]. Young mothers may have challenges with child care due to limited resources at their disposal which may subsequently result in poor health outcomes $[24,26]$. It is also likely that young mothers are at a disadvantage due to other age-related socio-demographic characteristics like education, employment status and marriage [5]. Our finding that a higher number of siblings is associated with increased anaemia is consistent with those observed in prior studies [24, 27]. A high number of children is likely to impact on women's ability to feed the children appropriately and subsequently trade quality for quantity in order to meet the needs of every member of the family [5, 27]. A higher number of children ever born per woman is also an indication of frequent pregnancy which may also increase the risk of anaemia. [5]. The wealth index has also been identified to be significantly associated with anaemia in young children in studies conducted in rural India and the United States [28, 29]. A common explanation for this observed pattern of relationship has been that malnutrition, deficiencies in other micronutrients, exposure to biofuel smoke and other unexplained characteristics associated with lower socioeconomic status may be a contributing factor [28-30].

In this study, maternal marital status is not significantly associated with the likelihood of anaemia in the general sample. Recent studies of under-five children in 
sub-Saharan Africa have shown similar findings where maternal marital status was not significantly associated with child health status [31, 32]. However, when the result is stratified by maternal educational attainment, our finding shows that the health disadvantage of having an unmarried mother is stronger for children whose mother has no education. The risk of anaemia for children whose mother has secondary or higher education is not significantly different across almost all other levels of the maternal socio-demographic characteristics. Similar relationships have been found in prior studies. For instance, Smith-Greenaway [13] in her study showed that premarital childbearing in the context of educational advantage does not bear the negative consequences that it does for children whose mothers are educationally disadvantaged. Moreover, increasing evidence from South Africa confirms that even in the absence of marriage, fathers are involved in the well-being of their children $[33,34]$. Building upon Smith-Greenaway's argument, it is possible that more educated unmarried mothers may be better positioned to receive support not only from a family member with greater resources but also from the child's father [13]. This finding suggests that improved maternal socio-economic conditions are essential for reducing the risk of anaemia among children under 5 years. As a crucial way for reducing the levels of anaemia, our findings coincide with those of previous studies and emphasize the need to invest in women's education as a way to enhance child well-being in developing countries [18].

It is however worth noting that information on the inherited disorder of haemoglobin structure among the children included in this study such as the case in sickle cell anaemia was not available in the dataset. As a result, it is possible that for some of the children their level of haemoglobin could have been influenced by genetic makeup rather than maternal socio-demographic characteristics.

\section{Conclusion}

The findings from this study underscore the fact that the prevalence of anaemia among under-five children in Tanzania is high especially in the Zanzibar region. Maternal characteristics including older age, higher education, access to health insurance, being employed and high household wealth are protective factors against anaemia among under-five children in Tanzania. We find that access to secondary or higher maternal education reduces the risks of anaemia among children of disadvantaged mothers. The health disadvantage of being born to an unmarried mother is aggravated only among children of women with no education.

Finally, the key recommendation emerging from this study is that programs aimed at reducing anaemia among children under-5 years in Tanzania especially the National Nutrition Strategy by the Ministry of Health and Social Welfare in the country should give special attention to young, males, and malnourished children. Children of unmarried, uneducated and unemployed mothers should also be targeted.

\section{Abbreviations}

BMI: Body Mass Index; Hb: Hemoglobin; HIV: Human immunodeficiency virus; NBS: National Bureau of Statistics; WHO: World Health Organization

\section{Acknowledgements \\ The authors gratefully acknowledge Dr. Nicole DeWet of the University of the Witwatersrand, South Africa and the participants of the WITS University Pop-Studies mini-conference for their comments. We also acknowledge the Measure DHS, all women and children who participated in this survey, the Tanzania National Bureau of Statistics, and other implementing partners for making available, the 2015-16 Tanzania demographic and health survey.}

Funding

Not applicable.

\section{Availability of data and materials}

Data used for this study was obtained from the demographic and health survey website (https://dhsprogram.com/what-we-do/survey/survey-display-485.cfm) and are completely anonymous in that all personal, confidential and identifying information or characteristics of the respondents had been meticulously cleaned to minimize any risk of harm that this may cause.

\section{Authors' contributions}

$\mathrm{OO}$ conceived and designed the study. $\mathrm{OO}$ and EOO downloaded and analyzed the data. OO, EO and JOA interpreted data. COO and JOA contributed to the writing of and reviewed the manuscript. All authors read and approved the final manuscript.

\section{Ethics approval and consent to participate}

This study was exempted from ethical review by the human research ethics committee (non-medical) of the University of the Witwatersrand, South Africa because the study used a de-identified open-source dataset.

\section{Consent for publication}

The Tanzania Demographic and Health survey is a de-identified open-source dataset. However, during the surveys, consent for interviews as well as biomarker measurements were from women as well as the parents or guardians of the children included in the study. Results of the biomarker measurements were given to each child's parent or guardian both verbally and in writing.

\section{Competing interests}

The authors declare that they have no competing interests.

\section{Publisher's Note}

Springer Nature remains neutral with regard to jurisdictional claims in published maps and institutional affiliations.

\section{Author details}

${ }^{1}$ Implementation Science Department, The Wits Reproductive Health \& HIV Institute, P.O Box 2193, Johannesburg, South Africa. ${ }^{2}$ Demography and Population Studies Programme, Schools of Social Sciences and Public Health, University of the Witwatersrand, Johannesburg, South Africa. ${ }^{3}$ Department of Statistics and Demography, Faculty of Social Sciences, University of Eswatini, Kwaluseni, Eswatini, Swaziland. ${ }^{4}$ Department of Epidemiology and Medical Statistics, College of Medicine, University of Ibadan, Ibadan, Nigeria.

Received: 30 November 2018 Accepted: 22 March 2019

Published online: 03 April 2019

References

1. Chatterjee ABR, Kupka R, Hunter DJ, Msamanga Gl, Fawzi WW. Predictors and consequences of anaemia among antiretroviral-naive HIV-infected and HIV-uninfected children in Tanzania. Public Health Nutr. 2010;13(2):289-96. 
2. Makubi AN, Mugus F, Magesa PM, Roberts D, Quaresh A: Risk factors for anemia among HIV infected children attending care and treatment clinic at Muhimbili National Hospital in Dar es Salaam, Tanzania. 2012, 14(1):68-74.

3. Simbauranga RH, Kamugisha E, Hokororo A, Kidenya BR, Makani J. Prevalence and factors associated with severe anaemia amongst under-five children hospitalized at Bugando Medical Centre, Mwanza, Tanzania. BMC hematology. 2015;15(1):1-9.

4. Benoist Bd, McLean E, Egll I, Cogswell M. Worldwide prevalence of anaemia 1993-2005: WHO global database on anaemia. Worldwide prevalence of anaemia 1993-2005: WHO global database on anaemia 2008.

5. Hobcraft JN. Women's education, child welfare and child survival: A review of the evidence. Health Transitions Review. 1993;3(2):159-75.

6. Mosley WH, Chen LC. An analytical framework for the study of child survival in developing countries. Popul Dev Rev. 1984;10:25

7. Kabagenyi A, Rutaremwa G. The effect of household characteristics on child mortality in Uganda. Am J Sociological Res. 2013;3(1):1-5.

8. Kabubo-Mariara J, Ndenge GK, Mwabu DK. Determinants of Children's nutritional status in Kenya: evidence from demographic and health surveys. J Afr Econ. 2009;18(3):363-87.

9. Basu AM, Stephenson R. Low levels of maternal education and the proximate determinants of childhood mortality: a little learning is not a dangerous thing. Soc Sci Med. 2005;60(9):2011-23.

10. Currie J, Moretti E. Mother's education and the intergenerational transmission of human capital: evidence from college openings. Q J Econ. 2003;118(4):1495-532.

11. Schnell-Anzola B, Rowe ML, LeVine RA. Literacy as a pathway between schooling and health-related communication skills: a study of Venezuelan mothers. Int J Educ Dev. 2005;25(1):19-37.

12. Ministry of Health CD, Gender, Elderly, Children - MoHCDGEC/Tanzania Mainland, Ministry of Health - MoH/Zanzibar, National Bureau of Statistics - NBS/ Tanzania, Office of Chief Government Statistician - OCGS/Zanzibar, ICF: Tanzania Demographic and Health Survey and Malaria Indicator Survey 2015-2016. In. Dar es Salaam, Tanzania: MoHCDGEC, MoH, NBS, OCGS, and ICF; 2016.

13. Smith-Greenaway E. Premarital childbearing in sub-Saharan Africa: can investing in women's education offset disadvantages for children? SSM Population Health. 2016;2:164-74.

14. Sharman A: Anemia testing in population-based surveys: General information and guidelines for country monitors and program managers. In. Calverton, Maryland USA.; 2000

15. Stoltzfus RJ. Defining iron-deficiency anemia in public health terms: a time for reflection. J Nutr. 2001;131(2):565S-7S.

16. McCullagh P. Regression models for ordinal data. J R Stat Soc Ser B Methodol. 1980;42(2):109-42.

17. Faul F, Erdfelder E, Lang A-G, Buchner A. G*power 3: a flexible statistical power analysis program for the social, behavioral, and biomedical sciences. Behav Res Methods. 2007:39(2):175-91.

18. Abubakar A, Uriyo J, Msuya SE, Swai M, Stray-Pedersen B. Prevalence and risk factors for poor nutritional status among children in the Kilimanjaro region of Tanzania. Int J Environ Res Public Health. 2012;9(10):3506-18. https://doi.org/10.3390/ijerph9103506.

19. Tanzania Food and Nutrition Centre: Tanzania National Nutrition Survey. In Dar es Salaam and Zanzibar, Tanzania: United Republic of Tanzania Ministry of Health and Social Welfare; 2014.

20. Ayoya MA, Ngnie-Teta I, Séraphin MN, Mamadoultaibou A, Boldon E, SaintFleur JE, Koo L, Bernard S. Prevalence and risk factors of Anemia among children 6-59 months old in Haiti. Anemia. 2013;2013:1-3.

21. Keikhaei B, Zandian K, Ghasemi A, Tabibi R. Iron-deficiency anemia among children in Southwest Iran. Food Nutr Bull. 2007;28(4):406-11.

22. Ngesa $\mathrm{O}, \mathrm{Mwambi} \mathrm{H}$. Prevalence and risk factors of anaemia among children aged between 6 months and 14 years in Kenya. PLoS One. 2014; 9(11):e113756

23. Leite MS, Cardoso AM, Coimbra CEA, Welch JR, Gugelmin SA, Lira PCl, Horta BL, Santos RV, Escobar AL. Prevalence of anemia and associated factors among indigenous children in Brazil: results from the first National Survey of indigenous People's health and nutrition. Nutr J. 2013;12(1):1.

24. Kuziga F, Adoke Y, Wanyenze RK. Prevalence and factors associated with anaemia among children aged 6 to 59 months in Namutumba district, Uganda: a cross- sectional study. BMC Pediatr. 2017;17(1):25.

25. Ahmad N, Kalakoti P, Bano R, Aarif SMM. The prevalence of anaemia and associated factors in pregnant women in a rural Indian community. Australasian Medical Journal. 2010;3(5):276-280.
26. Finlay JE, Ozaltin E, Canning D. The association of maternal age with infant mortality, child anthropometric failure, diarrhoea and anaemia for first births: evidence from 55 low- and middle-income countries. BMJ Open. 2011;1(2):e000226.

27. Conde-Agudelo A, Rosas-Bermudez A, Castaño F, Norton MH. Effects of birth spacing on maternal, perinatal, infant, and child health: a systematic review of causal mechanisms. Stud Fam Plan. 2012;43(2):93-114.

28. Skalicky A, Meyers AF, Adams WG, Yang Z, Cook JT, Frank DA. Child food insecurity and iron deficiency anemia in low-income infants and toddlers in the United States. Matern Child Health J. 2006;10(2):177-85.

29. Pasricha SR, Black J, Muthayya S, Shet A, Bhat V, Nagaraj S, Prashanth NS, Sudarshan H, Biggs BA, Shet AS. Determinants of anemia among young children in rural India. Pediatrics. 2010;126(1):e140-9.

30. Mishra $V$, Retherford RD. Does biofuel smoke contribute to anaemia and stunting in early childhood? Int J Epidemiol. 2007:36(1):117-29.

31. Olamijuwon E, Odimegwu CO, Gumbo J, Chisumpa V. Single motherhood and marasmus among under-five children in sub-Saharan Africa: a regional analysis of prevalence and correlates. Afr Popul Stud. 2017;31(1):3356-3368. https://doi.org/10.11564/31-1-994

32. Banda PC, Ntoimo LF, Olamijuwon EO. Living arrangements and nutritional status of under-five children in sub-Saharan Africa. Afr Popul Stud. 2017; 31(1):3639-3649. https://doi.org/10.11564/31-1-1029.

33. Clark S, Cotton C, Marteleto LJ. Family ties and young Fathers' engagement in Cape Town, South Africa. J Marriage Fam. 2015;77(2):575-89.

34. Madhavan S, Richter L, Norris S, Hosegood V. Fathers' financial support of children in a low income Community in South Africa. J Fam Econ Issues. 2014;35(4):452-63.

\section{Ready to submit your research? Choose BMC and benefit from:}

- fast, convenient online submission

- thorough peer review by experienced researchers in your field

- rapid publication on acceptance

- support for research data, including large and complex data types

- gold Open Access which fosters wider collaboration and increased citations

- maximum visibility for your research: over $100 \mathrm{M}$ website views per year

At BMC, research is always in progress.

Learn more biomedcentral.com/submissions 